\title{
ARTICLE
}

\section{Diabetes, prediabetes and cancer mortality}

\author{
X. H. Zhou • Q. Qiao • B. Zethelius • K. Pyörälä • \\ S. Söderberg • A. Pajak • C. D. A. Stehouwer • \\ R. J. Heine • P. Jousilahti • G. Ruotolo • P. M. Nilsson • \\ G. Calori • J. Tuomilehto • \\ for the DECODE Study Group
}

Received: 8 February 2010 /Accepted: 16 April 2010/Published online: 21 May 2010

(C) Springer-Verlag 2010

\begin{abstract}
Aims/hypothesis We aimed to investigate the risk of cancer mortality in relation to the glucose tolerance status classified according to the $2 \mathrm{~h}$ OGTT.

Methods Data from 17 European population-based or occupational cohorts involved in the DECODE study comprising 26,460 men and 18,195 women aged 25-90 years were collaboratively analysed. The cohorts were recruited between 1966 and 2004 and followed for 5.9 to 36.8 years. Cox
\end{abstract}

Electronic supplementary material The online version of this article (doi:10.1007/s00125-010-1796-7) contains details of the DECODE

Study Group which are available to authorised users.

X. H. Zhou $\cdot$ Q. Qiao $(\bowtie) \cdot J$. Tuomilehto

Department of Public Health, University of Helsinki,

PL41, Mannerheimintie 172,

Helsinki, Finland

e-mail: qing.qiao@helsinki.fi

\section{H. Zhou}

Department of Endocrinology and Metabolism,

Peking University People's Hospital,

Beijing, China

\section{H. Zhou}

Peking University Diabetes Centre,

Beijing, China

Q. Qiao $\cdot$ P. Jousilahti $\cdot$ J. Tuomilehto

Department of Chronic Disease Prevention,

National Institute for Health and Welfare,

Helsinki, Finland

\section{B. Zethelius}

Department of Public Health/Geriatrics,

Uppsala University Hospital,

Uppsala, Sweden

\section{K. Pyörälä}

Institute of Clinical Medicine, University of Eastern Finland,

Kuopio, Finland proportional hazards analysis with adjustment for cohort, age, BMI, total cholesterol, blood pressure and smoking status was used to estimate HRs for cancer mortality.

Results Compared with people in the normal glucose category, multivariable adjusted HRs $(95 \% \mathrm{CI})$ for cancer mortality were $1.13(1.00,1.28), 1.27(1.02,1.57)$ and $1.71(1.35,2.17)$ in men with prediabetes, previously undiagnosed diabetes and known diabetes, respectively; in women they were $1.11(0.94,1.30)$, $1.31(1.00,1.70)$ and $1.43(1.01,2.02)$, respectively. Significant

S. Söderberg

Department of Public Health and Clinical Medicine, Medicine, University of Umeå, and Heart Centre, Umeå University Hospital, Umeå, Sweden

S. Söderberg

Baker IDI Heart and Diabetes Institute,

Melbourne, Australia

A. Pajak

Department of Epidemiology and Population Studies, Institute of Public Health, Faculty of Health Sciences, Jagiellonian University Medical College, Krakow, Poland

C. D. A. Stehouwer

Department of Internal Medicine and Cardiovascular Research Institute Maastricht (CARIM),

Maastricht University Medical Centre,

AZ Maastricht, the Netherlands

R. J. Heine

EMGO Institute for Health and Care Research,

VU University Medical Centre,

Amsterdam, the Netherlands 
increases in deaths from cancer of the stomach, colonrectum and liver in men with prediabetes and diabetes, and deaths from cancers of the liver and pancreas in women with diabetes were also observed. In individuals without known diabetes, the HR $(95 \% \mathrm{CI})$ for cancer mortality corresponding to a one standard deviation increase in fasting plasma glucose was $1.06(1.02,1.09)$ and in $2 \mathrm{~h}$ plasma glucose was $1.07(1.03,1.11)$.

Conclusions/interpretation Diabetes and prediabetes were associated with an increased risk of cancer death, particularly death from liver cancer. Mortality from all cancers rose linearly with increasing glucose concentrations.

Keywords Cancer $\cdot$ Diabetes $\cdot$ Mortality

$\begin{array}{ll}\text { Abbreviations } \\ \text { 2-hPG } & 2 \text { h Plasma glucose } \\ \text { DECODE } & \begin{array}{l}\text { Diabetes Epidemiology: Collaborative analysis } \\ \text { Of Diagnostic criteria in Europe }\end{array} \\ \text { FPG } & \text { Fasting plasma glucose } \\ \text { MPP } & \text { Malmö Preventive Project } \\ \text { NGT } & \text { Normal glucose tolerance } \\ \text { NHANES } & \text { National Health and Nutrition Examination } \\ & \text { Survey }\end{array}$

\section{Introduction}

Epidemiological studies have shown that diabetes [1-7] or certain treatments for diabetes may increase the risk [8-10] of developing cancer. Diabetes may also affect the treatment of cancer; some types of cancer are treated less aggressively in patients with diabetes than in patients without diabetes [11].

\footnotetext{
R. J. Heine

Eli Lilly and Company,

Indianapolis, IN, USA

G. Ruotolo · G. Calori

Division of Metabolic and Cardiovascular Diseases,

San Raffaele Scientific Institute,

Milan, Italy

G. Ruotolo

AstraZeneca R\&D Mölndal,

Mölndal, Sweden

P. M. Nilsson

Department of Clinical Sciences, Lund University,

University Hospital,

Malmö, Sweden

J. Tuomilehto

South Ostrobothnia Central Hospital,

Seinäjoki, Finland

Evidence for the association between diabetes and cancerrelated mortality is, however, still limited and results from different studies are controversial. It was reported that diabetic patients suffered from higher mortality rates from all cancers [12] or some types of cancers $[13,14]$ than the general population. Pre-existing diabetes was a risk factor for allcancer death in Japanese women [15] and for death from some types of cancers in a US population [16]. No association between diabetes and all-cancer mortality was found in an occupational male group (Whitehall study) in the UK [17] or in the Second National Health and Nutrition Examination Survey (NHANES II) Mortality Study in the USA [18]. The NHANES II has, however, found IGT to be associated with a higher risk of cancer mortality. Cancer mortality may also increase with increasing fasting [19, 20], non-fasting [20] or postload [21] glucose levels.

The aim of this study was to investigate the risk of cancer mortality in relation to the glucose tolerance status based on data from the Diabetes Epidemiology: Collaborative analysis of Diagnostic criteria in Europe (DECODE) Study.

\section{Methods}

The study populations and the methods used to recruit participants for the DECODE study have been reported previously $[22,23]$. In brief, researchers in Europe who had performed population-based studies or large studies in occupational groups using the standard $2 \mathrm{~h} 75 \mathrm{~g}$ OGTT were invited to participate in the DECODE study. In the current study, 15,631 participants (12,999 men and 2,632 women) from the Malmö Preventive Project (MPP, Sweden) who underwent $2 \mathrm{~h}$ OGTT using $30 \mathrm{~g}$ oral glucose load per body surface area $\left(\mathrm{m}^{2}\right)$ [24] were also included. Individual data from each study cohort were sent to the Diabetes Prevention Unit of the National Institute for Health and Welfare in Helsinki, Finland, for data analyses. Each study was approved by the local ethics committees and the analysis plan was approved by the ethics committee of the National Institute for Health and Welfare.

A total of 44,655 participants from 17 study cohorts with prospective data on cause-specific mortality and all other required variables of fasting plasma glucose (FPG), $2 \mathrm{~h}$ plasma glucose (2-hPG) after a glucose load, BMI, total serum cholesterol, blood pressure and smoking status were included in the current data analyses. All 17 study cohorts included men $(n=26,460)$ and 14 also included women $(n=18,195)$. The baseline age of the participants ranged from 25 to 90 years with mean ages varying from 45 to 76 years in different study cohorts. The study cohorts were recruited between 1966 and 2004 and followed up for 5.9 to 36.8 years, with median 
(25th, 75th percentile) follow up of 15.8 years (9.1, 23.2 years) in all cohorts combined (Table 1). Men contributed 467,872 person-years and women contributed 252,503 person-years of follow up. Informed consent was obtained from all participants in each study.

In the current study population, participants who had a prior history of diabetes or who were on antihyperglycaemic treatment before the baseline survey were considered as having known diabetes. Participants without known diabetes at the baseline survey were classified according to the World Health Organization definition [25]. Undiagnosed diabetes is defined as having either $\mathrm{FPG} \geq$ $7.0 \mathrm{mmol} / 1 \mathrm{and} /$ or $2-\mathrm{hPG} \geq 11.1 \mathrm{mmol} / \mathrm{l}$. IGT is defined as having $\mathrm{FPG}<7.0 \mathrm{mmol} / \mathrm{l}$ and $2-\mathrm{hPG} \geq 7.8 \mathrm{mmol} / \mathrm{l}$ but $<11.1 \mathrm{mmol} / \mathrm{l}$. IFG is defined as having $\mathrm{FPG} \geq 6.1 \mathrm{mmol} / \mathrm{l}$ but $<7.0 \mathrm{mmol} / \mathrm{l}$ and $2-\mathrm{hPG}<7.8 \mathrm{mmol} / \mathrm{l}$. NGT is defined as FPG $<6.1 \mathrm{mmol} / 1$ and $2-\mathrm{hPG}<7.8 \mathrm{mmol} / \mathrm{l}$. People with IGT and/or IFG were labelled as having 'prediabetes'.

Vital status and the cause of death were obtained from national cause-of-death registers or from medical records if the register was not available in some countries for each participant in all studies. Participants who emigrated, for whom the vital status could not be confirmed, were considered as censored cases. Cancer death was defined by the International Classification of Disease codes 140-207 and 209 (8th revision), codes 140-208 (9th revision) and codes C00-C97 (10th revision). No data on autopsy was provided.

Statistical methods Statistical analysis was performed using the SPSS for Windows version 15.0 (SPSS Inc, Chicago, IL, USA) and STATA version 9.2 (StataCorp, College Station, TX, USA). Means and differences in means between groups were estimated using univariate general linear models with adjustments for age and study for continuous variables. $\chi^{2}$ test was used to test differences in proportions between groups. Crude mortality rates per 1,000 person-years were calculated for each glucose tolerance category. HRs and their $95 \%$ CIs for cancer death were estimated using a Cox proportional hazards model for different glucose intolerance groups at the presence of

Table 1 Mean $( \pm \mathrm{SD})$ age at baseline and number $(\%)$ of cancer deaths during the follow-up in each study cohort

\begin{tabular}{|c|c|c|c|c|c|c|}
\hline \multirow[t]{2}{*}{ Study cohort } & \multirow{2}{*}{$\begin{array}{l}\text { Men } \\
(n)\end{array}$} & \multirow{2}{*}{$\begin{array}{l}\text { Women } \\
(n)\end{array}$} & \multirow{2}{*}{$\begin{array}{l}\text { Age } \\
\text { (years) }\end{array}$} & \multicolumn{2}{|c|}{ Cancer deaths $(n)$} & \multirow{2}{*}{$\begin{array}{l}\text { Maximum follow-up } \\
\text { (years) }\end{array}$} \\
\hline & & & & Men & Women & \\
\hline \multicolumn{7}{|l|}{ Denmark } \\
\hline Glostrup [35] & 1,050 & 1,029 & $52.1 \pm 12.2$ & $109(10.4)$ & $88(8.6)$ & 27.0 \\
\hline \multicolumn{7}{|l|}{ Finland } \\
\hline East-West Finland $^{\mathrm{a}}[36]$ & 405 & - & $76.2 \pm 4.5$ & $70(17.3)$ & - & 17.1 \\
\hline FINRISK-1987 [37] & 1,261 & 1,440 & $54.0 \pm 5.7$ & $119(9.4)$ & $90(6.3)$ & 20.9 \\
\hline FINRISK-1992 [37] & 877 & 1,041 & $54.1 \pm 6.0$ & $44(5.0)$ & $53(5.1)$ & 16.0 \\
\hline FINRISK-2002 [38] & 1,786 & 2,055 & $57.9 \pm 7.8$ & $35(2.0)$ & $18(0.9)$ & 5.9 \\
\hline Helsinki policemen ${ }^{a}$ [39] & 1,136 & - & $44.7 \pm 8.0$ & $175(15.4)$ & - & 36.8 \\
\hline Oulu [40] & 418 & 603 & $60.9 \pm 9.7$ & $21(5.0)$ & $12(2.0)$ & 15.0 \\
\hline Vantaa [41] & 271 & 335 & $65.1 \pm 0.4$ & $22(8.1)$ & $19(5.7)$ & 17.9 \\
\hline \multicolumn{7}{|l|}{ Italy } \\
\hline Cremona [42] & 800 & 999 & $58.4 \pm 10.8$ & $102(12.8)$ & $63(6.3)$ & 15.7 \\
\hline \multicolumn{7}{|l|}{ The Netherlands } \\
\hline Hoorn [43] & 1,116 & 1,317 & $61.6 \pm 7.3$ & $62(5.6)$ & $52(3.9)$ & 10.2 \\
\hline \multicolumn{7}{|l|}{ Poland } \\
\hline Krakow [44] & 163 & 186 & $57.8 \pm 8.3$ & $3(1.8)$ & $3(1.6)$ & 6.6 \\
\hline \multicolumn{7}{|l|}{ Sweden } \\
\hline Northern Sweden MONICA Survey [45] & 1,733 & 1,760 & $48.9 \pm 13.4$ & $42(2.4)$ & $33(1.9)$ & 20.6 \\
\hline Malmö (MPP) [24] & 12,999 & 5,881 & $49.6 \pm 4.9$ & $1,381(10.6)$ & $367(6.2)$ & 30.3 \\
\hline Uppsala $^{\mathrm{a}}[46]$ & 1,164 & - & $71.0 \pm 0.6$ & $123(10.6)$ & - & 12.4 \\
\hline \multicolumn{7}{|l|}{ UK } \\
\hline Cambridge (Ely) [47] & 435 & 607 & $54.0 \pm 7.8$ & $19(4.4)$ & $30(4.9)$ & 15.7 \\
\hline Goodinge [48] & 448 & 566 & $54.6 \pm 10.3$ & $19(4.2)$ & $27(4.8)$ & 9.7 \\
\hline Newcastle [49] & 398 & 376 & $54.8 \pm 12.5$ & $19(4.8)$ & $15(4.0)$ & 10.6 \\
\hline Total & 26,460 & 18,195 & $53.4 \pm 9.5$ & $2,365(8.9)$ & $870(4.8)$ & 36.8 \\
\hline
\end{tabular}

${ }^{\mathrm{a}}$ The cohort includes only men 
covariates of study cohort, age at baseline (years), BMI $\left(\mathrm{kg} / \mathrm{m}^{2}\right)$, systolic blood pressure $(\mathrm{mmHg})$, serum cholesterol $(\mathrm{mmol} / \mathrm{l})$ and smoking status. Stratified analysis by the BMI tertiles was also made for different glucose intolerance groups adjusting for study cohort, age, sex, systolic blood pressure, serum cholesterol and smoking status. Fasting insulin was analysed in only a subgroup of men $(n=15,227)$ and women $(n=9,221)$ who had fasting insulin measured at baseline survey. Time since baseline was used as the time-scale in the Cox proportional hazards model. Interaction between the glucose intolerance and smoking status was examined to evaluate whether the effect of glucose intolerance on cancer mortality differed in smokers from that in non-smokers.

The HRs $(95 \%$ CIs) for cancer death corresponding to a study-specific one standard deviation (SD) increase in linear form of the FPG and 2-hPG in individuals without a prior history of diabetes were also estimated for each study adjusting for age, sex, BMI, systolic blood pressure, cholesterol and smoking status. Heterogeneity between studies was assessed using Cochran's $Q$ statistics and $I^{2}$ statistics, a transformation of $Q$ that estimates the percentage of total variation across studies that is due to heterogeneity [26]. An overall HR for all studies combined was then calculated using the MantelHaenszel method for a fixed-effect model. The influence of individual studies on the overall estimate was assessed by calculating pooled HRs while omitting one study at a time.

\section{Results}

Individuals who died from cancer were older, less obese and comprised a higher proportion of current smokers than others
(Table 2). A total of 2,365 cancer deaths were documented in men during a median follow-up of 18.0 years and 870 cancer deaths were recorded in women during 14.9 years. Agestandardised all-cancer mortality rate was higher in individuals with diabetes than in those without in both sexes (Table 3).

Compared with NGT, the multivariable-adjusted HRs $(95 \% \mathrm{CI})$ for all-cancer death increased with worsening glucose intolerance status; they were $1.13(1.00,1.28)$ for prediabetes, $1.27(1.02,1.57)$ for previously undiagnosed diabetes and $1.71(1.35,2.17)$ for known diabetes in men. The results were similar in women (Table 3 ). The multivariableadjusted HR for site-specific cancer death was estimated when more than 90 events accumulated in a cancer subgroup. Certain types of site-specific cancers were combined in the final data analyses because of the low numbers in each group. Compared with individuals with NGT, the HR was higher for death from cancers in stomach, colon-rectum and liver in men with prediabetes and diabetes, and for deaths from cancers in liver and pancreas in women; however, this increase was only of borderline significance in women with prediabetes and undiagnosed diabetes (Table 3). The interaction term between glucose intolerance and smoking was not statistically significant, i.e. smoking did not modify the effect of glucose intolerance on cancer.

The multivariable-adjusted HRs for all-cancer death was also estimated within each BMI tertile. Compared with NGT, the HRs $(95 \%$ CIs $)$ were $1.14(0.96,1.36)$ for prediabetes, $1.15(0.76,1.73)$ for previously undiagnosed diabetes and $1.58(1.06,2.35)$ for known diabetes in individuals in the lowest tertile of BMI $\left(<24.0 \mathrm{~kg} / \mathrm{m}^{2}\right)$; they were $1.27(1.08$, $1.50), 1.12(0.79,1.59)$ and $1.69(1.16,2.46)$ in the middle
Table 2 Baseline characteristics of men and women by all-cancer death

Data are cohort-adjusted and age-adjusted mean $\pm \mathrm{SE}$ or $n(\%)$

Prediabetes included impaired fasting glucose and/or impaired glucose tolerance

${ }^{\mathrm{a}} p<0.001,{ }^{\mathrm{b}} p<0.05$ for the difference between groups with and without cancer death

\begin{tabular}{|c|c|c|c|c|}
\hline \multirow[t]{2}{*}{ Variable } & \multicolumn{2}{|c|}{ Cancer death in men } & \multicolumn{2}{|c|}{ Cancer death in women } \\
\hline & No & Yes & No & Yes \\
\hline$n(\%)$ & $24,095(91.1)$ & $2,365(8.9)$ & $17,325(95.2)$ & $870(4.8)$ \\
\hline Age (years) & $52.0 \pm 0.1$ & $54.2 \pm 0.2^{\mathrm{a}}$ & $54.9 \pm 0.1$ & $57.4 \pm 0.3^{\mathrm{a}}$ \\
\hline BMI $\left(\mathrm{kg} / \mathrm{m}^{2}\right)$ & $25.9 \pm 0.02$ & $25.5 \pm 0.1^{\mathrm{a}}$ & $26.3 \pm 0.04$ & $25.9 \pm 0.2^{b}$ \\
\hline \multicolumn{5}{|l|}{ Blood pressure $(\mathrm{mmHg})$} \\
\hline Systolic & $135 \pm 0.1$ & $135 \pm 0.4$ & $134 \pm 0.1$ & $133 \pm 0.7^{\mathrm{b}}$ \\
\hline Diastolic & $85 \pm 0.1$ & $86 \pm 0.2$ & $81 \pm 0.1$ & $81 \pm 0.4$ \\
\hline Cholesterol (mmol/1) & $5.9 \pm 0.01$ & $5.9 \pm 0.02$ & $6.2 \pm 0.01$ & $6.3 \pm 0.04^{\mathrm{a}}$ \\
\hline \multicolumn{5}{|c|}{ Glucose tolerance status, $n(\%)$} \\
\hline Normal glucose tolerance & $18,169(75.4)$ & $1,817(76.8)$ & $10,879(62.8)$ & $518(59.5)$ \\
\hline Prediabetes & $4,149(17.2)$ & $372(15.7)$ & $4,746(27.4)$ & $246(28.3)$ \\
\hline Undiagnosed diabetes & $1,075(4.5)$ & $95(4.0)$ & $1,129(6.5)$ & $67(7.7)$ \\
\hline Known diabetes & $702(2.9)$ & $81(3.4)$ & $571(3.3)$ & $39(4.5)$ \\
\hline \multicolumn{5}{|l|}{ Smoking status, $n(\%)$} \\
\hline Current smoker & $9,386(39.0)$ & $1,310(55.4)^{\mathrm{a}}$ & $4,208(24.3)$ & $314(36.1)^{\mathrm{a}}$ \\
\hline Ex-smoker & $4,586(19.0)$ & $327(13.8)$ & $2,730(15.8)$ & $108(12.4)$ \\
\hline
\end{tabular}


Table 3 Crude cancer mortality (per 1,000 person-years) and multivariable-adjusted HR in relation to glucose tolerance status in men and women

\begin{tabular}{|c|c|c|c|c|c|}
\hline Type of cancer & NGT & Prediabetes & Undiagnosed diabetes & Known diabetes & All diabetes \\
\hline \multicolumn{6}{|l|}{ Men } \\
\hline \multicolumn{6}{|l|}{ All cancers } \\
\hline No. of deaths & 1,817 & 372 & 95 & 81 & 176 \\
\hline Mortality & 4.76 & 5.69 & 6.92 & 11.67 & 8.52 \\
\hline $\operatorname{HR}(95 \% \mathrm{CI})^{\mathrm{a}}$ & 1.0 & $1.13(1.00,1.28)$ & $1.27(1.02,1.57)$ & $1.71(1.35,2.17)$ & $1.44(1.21,1.70)$ \\
\hline \multicolumn{6}{|c|}{ Stomach or colon-rectum } \\
\hline No. of deaths & 258 & 70 & 19 & 17 & 36 \\
\hline Mortality & 0.68 & 1.07 & 1.38 & 2.45 & 1.74 \\
\hline $\operatorname{HR}(95 \% \mathrm{CI})^{\mathrm{a}}$ & 1.0 & $1.46(1.09,1.94)$ & $1.69(1.03,2.76)$ & $2.07(1.21,3.51)$ & $1.84(1.25,2.71)$ \\
\hline \multicolumn{6}{|l|}{ Liver } \\
\hline No. of deaths & 42 & 17 & 6 & 9 & 15 \\
\hline Mortality & 0.11 & 0.26 & 0.44 & 1.30 & 0.73 \\
\hline $\operatorname{HR}(95 \% \mathrm{CI})^{\mathrm{a}}$ & 1.0 & $2.32(1.25,4.33)$ & $3.61(1.42,9.19)$ & $7.50(3.21,17.54)$ & $5.16(2.56,10.41)$ \\
\hline \multicolumn{6}{|l|}{ Pancreas } \\
\hline No. of deaths & 138 & 24 & 9 & 7 & 16 \\
\hline Mortality & 0.36 & 0.37 & 0.66 & 1.01 & 0.77 \\
\hline $\operatorname{HR}(95 \% \mathrm{CI})^{\mathrm{a}}$ & 1.0 & $0.88(0.56,1.41)$ & $1.52(0.74,3.12)$ & $1.92(0.85,4.33)$ & $1.67(0.94,2.97)$ \\
\hline \multicolumn{6}{|l|}{ Bronchus and lung } \\
\hline No. of deaths & 497 & 88 & 15 & 10 & 25 \\
\hline Mortality & 1.30 & 1.35 & 1.09 & 1.44 & 1.21 \\
\hline $\operatorname{HR}(95 \% \mathrm{CI})^{\mathrm{a}}$ & 1.0 & $1.14(0.89,1.46)$ & $0.85(0.50,1.45)$ & $0.93(0.49,1.78)$ & $0.88(0.58,1.35)$ \\
\hline \multicolumn{6}{|l|}{ Prostate } \\
\hline No. of deaths & 209 & 52 & 14 & 13 & 27 \\
\hline Mortality & 0.55 & 0.79 & 1.02 & 1.87 & 1.31 \\
\hline $\operatorname{HR}(95 \% \mathrm{CI})^{\mathrm{a}}$ & 1.0 & $1.01(0.73,1.40)$ & $1.09(0.62,1.93)$ & $1.64(0.90,2.99)$ & $1.30(0.84,2.01)$ \\
\hline \multicolumn{6}{|l|}{ Kidney or bladder } \\
\hline No. of deaths & 119 & 14 & 5 & 6 & 11 \\
\hline Mortality & 0.31 & 0.21 & 0.36 & 0.86 & 0.53 \\
\hline $\operatorname{HR}(95 \% \mathrm{CI})^{\mathrm{a}}$ & 1.0 & $0.59(0.33,1.05)$ & $0.84(0.33,2.13)$ & $1.93(0.79,4.71)$ & $1.20(0.61,2.37)$ \\
\hline \multicolumn{6}{|l|}{ Women } \\
\hline \multicolumn{6}{|l|}{ All cancers } \\
\hline No. of deaths & 518 & 246 & 67 & 39 & 106 \\
\hline Mortality & 3.17 & 3.63 & 4.42 & 6.60 & 5.04 \\
\hline $\operatorname{HR}(95 \% \mathrm{CI})^{\mathrm{a}}$ & 1.0 & $1.11(0.94,1.30)$ & $1.31(1.00,1.70)$ & $1.43(1.01,2.02)$ & $1.35(1.08,1.68)$ \\
\hline \multicolumn{6}{|c|}{ Stomach or colon-rectum } \\
\hline No. of deaths & 66 & 40 & 3 & 2 & 5 \\
\hline Mortality & 0.40 & 0.59 & 0.20 & 0.34 & 0.24 \\
\hline $\operatorname{HR}(95 \% \mathrm{CI})^{\mathrm{a}}$ & 1.0 & $1.52(1.00,2.31)$ & $0.49(0.15,1.59)$ & $0.46(0.11,1.93)$ & $0.48(0.19,1.21)$ \\
\hline \multicolumn{6}{|l|}{ Liver } \\
\hline No. of deaths & 8 & 5 & 3 & 6 & 9 \\
\hline Mortality & 0.05 & 0.07 & 0.20 & 1.02 & 0.43 \\
\hline $\operatorname{HR}(95 \% \mathrm{CI})^{\mathrm{a}}$ & 1.0 & $1.58(0.49,5.09)$ & $3.67(0.89,15.12)$ & $10.87(3.16,37.39)$ & $6.37(2.18,18.62)$ \\
\hline \multicolumn{6}{|l|}{ Pancreas } \\
\hline No. of deaths & 47 & 21 & 7 & 6 & 13 \\
\hline Mortality & 0.29 & 0.31 & 0.46 & 1.02 & 0.62 \\
\hline $\operatorname{HR}(95 \% \mathrm{CI})^{\mathrm{a}}$ & 1.0 & $1.08(0.63,1.85)$ & $1.71(0.74,3.94)$ & $3.13(1.21,8.08)$ & $2.13(1.09,4.16)$ \\
\hline \multicolumn{6}{|l|}{ Bronchus and lung } \\
\hline No. of deaths & 81 & 38 & 8 & 3 & 11 \\
\hline Mortality & 0.50 & 0.56 & 0.53 & 0.51 & 0.52 \\
\hline
\end{tabular}


Table 3 (continued)

\begin{tabular}{|c|c|c|c|c|c|}
\hline Type of cancer & NGT & Prediabetes & Undiagnosed diabetes & Known diabetes & All diabetes \\
\hline $\operatorname{HR}(95 \% \mathrm{CI})^{\mathrm{a}}$ & 1.0 & $1.12(0.75,1.69)$ & $1.03(0.49,2.19)$ & $0.72(0.21,2.43)$ & $0.93(0.48,1.81)$ \\
\hline \multicolumn{6}{|l|}{ Breast } \\
\hline No. of deaths & 68 & 42 & 12 & 5 & 17 \\
\hline Mortality & 0.42 & 0.62 & 0.79 & 0.85 & 0.81 \\
\hline $\operatorname{HR}(95 \% \mathrm{CI})^{\mathrm{a}}$ & 1.0 & $1.47(0.97,2.22)$ & $1.76(0.92,3.35)$ & $1.44(0.55,3.76)$ & $1.65(0.93,2.93)$ \\
\hline \multicolumn{6}{|l|}{ Kidney or bladder } \\
\hline No. of deaths & 17 & 12 & 2 & 5 & 7 \\
\hline Mortality & 0.10 & 0.18 & 0.13 & 0.85 & 0.33 \\
\hline $\operatorname{HR}(95 \% \mathrm{CI})^{\mathrm{a}}$ & 1.0 & $1.46(0.67,3.21)$ & $1.03(0.23,4.61)$ & $3.62(1.09,11.97)$ & $1.97(0.75,5.15)$ \\
\hline \multicolumn{6}{|l|}{ Total } \\
\hline No. of deaths & 2,335 & 618 & 162 & 120 & 282 \\
\hline Mortality & 4.28 & 4.64 & 5.61 & 9.34 & 6.76 \\
\hline $\operatorname{HR}(95 \% \mathrm{CI})^{\mathrm{a}}$ & 1.0 & $1.12(1.02,1.23)$ & $1.28(1.08,1.51)$ & $1.57(1.29,1.91)$ & $1.38(1.21,1.58)$ \\
\hline \multicolumn{6}{|c|}{ Stomach or colon-rectum } \\
\hline No. of deaths & 324 & 110 & 22 & 19 & 41 \\
\hline Mortality & 0.59 & 0.83 & 0.76 & 1.48 & 0.98 \\
\hline $\operatorname{HR}(95 \% \mathrm{CI})^{\mathrm{a}}$ & 1.0 & $1.46(1.15,1.84)$ & $1.24(0.79,1.94)$ & $1.46(0.89,2.39)$ & $1.33(0.94,1.89)$ \\
\hline \multicolumn{6}{|l|}{ Liver } \\
\hline No. of deaths & 50 & 22 & 9 & 15 & 24 \\
\hline Mortality & 0.09 & 0.17 & 0.31 & 1.17 & 0.58 \\
\hline $\operatorname{HR}(95 \% \mathrm{CI})^{\mathrm{a}}$ & 1.0 & $2.01(1.17,3.44)$ & $3.51(1.63,7.55)$ & $8.47(4.25,16.86)$ & $5.38(3.03,9.53)$ \\
\hline \multicolumn{6}{|l|}{ Pancreas } \\
\hline No. of deaths & 185 & 45 & 16 & 13 & 29 \\
\hline Mortality & 0.34 & 0.34 & 0.55 & 1.01 & 0.70 \\
\hline $\operatorname{HR}(95 \% \mathrm{CI})^{\mathrm{a}}$ & 1.0 & $1.02(0.72,1.44)$ & $1.67(0.97,2.85)$ & $2.34(1.27,4.32)$ & $1.90(1.24,2.93)$ \\
\hline \multicolumn{6}{|l|}{ Bronchus and lung } \\
\hline No. of deaths & 578 & 126 & 23 & 13 & 36 \\
\hline Mortality & 1.06 & 0.95 & 0.80 & 1.01 & 0.86 \\
\hline $\operatorname{HR}(95 \% \mathrm{CI})^{\mathrm{a}}$ & 1.0 & $1.11(0.90,1.37)$ & $0.90(0.58,1.38)$ & $0.87(0.49,1.54)$ & $0.89(0.62,1.27)$ \\
\hline \multicolumn{6}{|l|}{ Kidney or bladder } \\
\hline No. of deaths & 136 & 26 & 7 & 11 & 18 \\
\hline Mortality & 0.25 & 0.20 & 0.24 & 0.86 & 0.43 \\
\hline $\operatorname{HR}(95 \% \mathrm{CI})^{\mathrm{a}}$ & 1.0 & $0.82(0.52,1.27)$ & $0.90(0.41,1.98)$ & $2.45(1.23,4.88)$ & $1.44(0.83,2.47)$ \\
\hline
\end{tabular}

Prediabetes included impaired fasting glucose and/or impaired glucose tolerance

${ }^{a}$ Adjusted for study cohort, age, sex (when men and women are combined), BMI, systolic blood pressure, cholesterol and smoking status

NGT, normal glucose tolerance

tertile (BMI 24.0-27.1 kg/m²) and $0.99(0.85,1.16), 1.36$ $(1.09,1.69)$ and $1.51(1.14,2.00)$ in the upper tertile of the BMI distribution (BMI $\geq 27.2 \mathrm{~kg} / \mathrm{m}^{2}$ ). The risk of all-cancer deaths therefore increased in individuals with diabetes irrespective of their BMI levels.

After adding fasting insulin into the multivariable model in a subgroup of individuals, we obtained HRs (95\% CIs) of $1.18(1.02,1.38), 1.34(1.04,1.74)$ and $1.52(1.09,2.12)$ in men with prediabetes, undiagnosed and diagnosed diabetes for all-cancer deaths; while these were 1.19 $(1.03,1.38), 1.36(1.05,1.76)$ and $1.58(1.14,2.18)$, respectively, when fasting insulin was not fitted in the model. In women, these values were $1.20(0.92,1.56), 1.23$ $(0.79,1.91)$ and $1.71(1.00,2.93)$ after addition of fasting insulin and $1.21(0.92,1.58), 1.26(0.81,1.95)$ and 1.91 $(1.13,3.21)$ before adjusting for fasting insulin. The results therefore did not change substantially after adding fasting insulin into the multivariable model.

After excluding the cancer deaths that occurred within 5 years after the baseline examination, the HRs $(95 \%$ CIs) for all-cancer death were $1.10(0.96,1.26)$ for prediabetes, $1.27(0.99,1.62)$ for previously undiagnosed diabetes and $1.62(1.21,2.18)$ for known diabetes in men; they were $1.03(0.86,1.24), 1.25(0.92,1.69)$ and 
Fig. 1 HR (black circle) and 95\% CI (horizontal line) of allcancer death corresponding to a study-specific one SD increase in fasting plasma glucose for each study cohort and for all cohorts pooled together. The size of the square is proportional to the percentage weight of each study cohort

\begin{tabular}{llll} 
Study & Hazard & $\%$ \\
ratio (95\% CI) & Weight \\
Denmark, Glostrup [35] & & $0.93(0.76-1.14)$ & 3.28 \\
Finland, East-West Finland [36] & $0.94(0.71-1.23)$ & 1.75 \\
Finland, FINRISK-1987 [37] & $1.12(1.00-1.25)$ & 10.74 \\
Finland, FINRISK-1992 [37] & $1.10(0.91-1.33)$ & 3.54 \\
Finland, FINRISK-2002 [38] & $1.09(0.84-1.41)$ & 1.92 \\
Finland, Helsinki policemen [39] & $0.95(0.81-1.12)$ & 4.90 \\
Finland, Oulu [40] & $0.88(0.60-1.30)$ & 0.85 \\
Finland, Vantaa [41] & $1.02(0.73-1.44)$ & 1.11 \\
Italy, Cremona [42] & $1.02(0.89-1.18)$ & 6.37 \\
The Netherlands, Hoorn [43] & $1.17(1.04-1.32)$ & 9.37 \\
Poland, Krakow [44] & $1.16(0.50-2.70)$ & 0.18 \\
Sweden, Northern Sweden MONICA Survey [45] & $1.06(0.86-1.31)$ & 2.86 \\
Sweden, Malmö (MPP) [24] & $1.06(1.00-1.11)$ & 44.35 \\
Sweden, Uppsala [46] & $0.99(0.82-1.20)$ & 3.47 \\
UK, Cambridge (Ely) [47] & $0.90(0.65-1.24)$ & 1.21 \\
UK, Goodinge [48] & $1.13(0.94-1.35)$ & 3.80 \\
UK, Newcastle [49] & & $0.69(0.36-1.30)$ & 0.32 \\
Overall ( $\left.{ }^{2}=0.0 \%, p=0.682\right)$ & $1.06(1.02-1.09)$ & 100.00 \\
& & \\
\hline
\end{tabular}

$I^{2}=0.0 \%, p=0.68$ for FPG and $Q=17.0$ on $16 d f, I^{2}=5.9 \%$, $p=0.38$ for 2-hPG). Multivariate-adjusted overall HRs (95\% CIs) for all-cancer death were $1.06(1.02,1.09)$ and $1.07(1.03,1.11)$ corresponding to a one SD increase in FPG and 2-hPG, respectively (Figs 1 and 2). Leaving any one study out from the data analyses did not substantially
Fig. 2 HR (black circle) and 95\% CI (horizontal line) of allcancer death corresponding to a study-specific one SD increase in $2 \mathrm{~h}$ plasma glucose for each study cohort and for all cohorts pooled together. The size of the square is proportional to the percentage weight of each study cohort

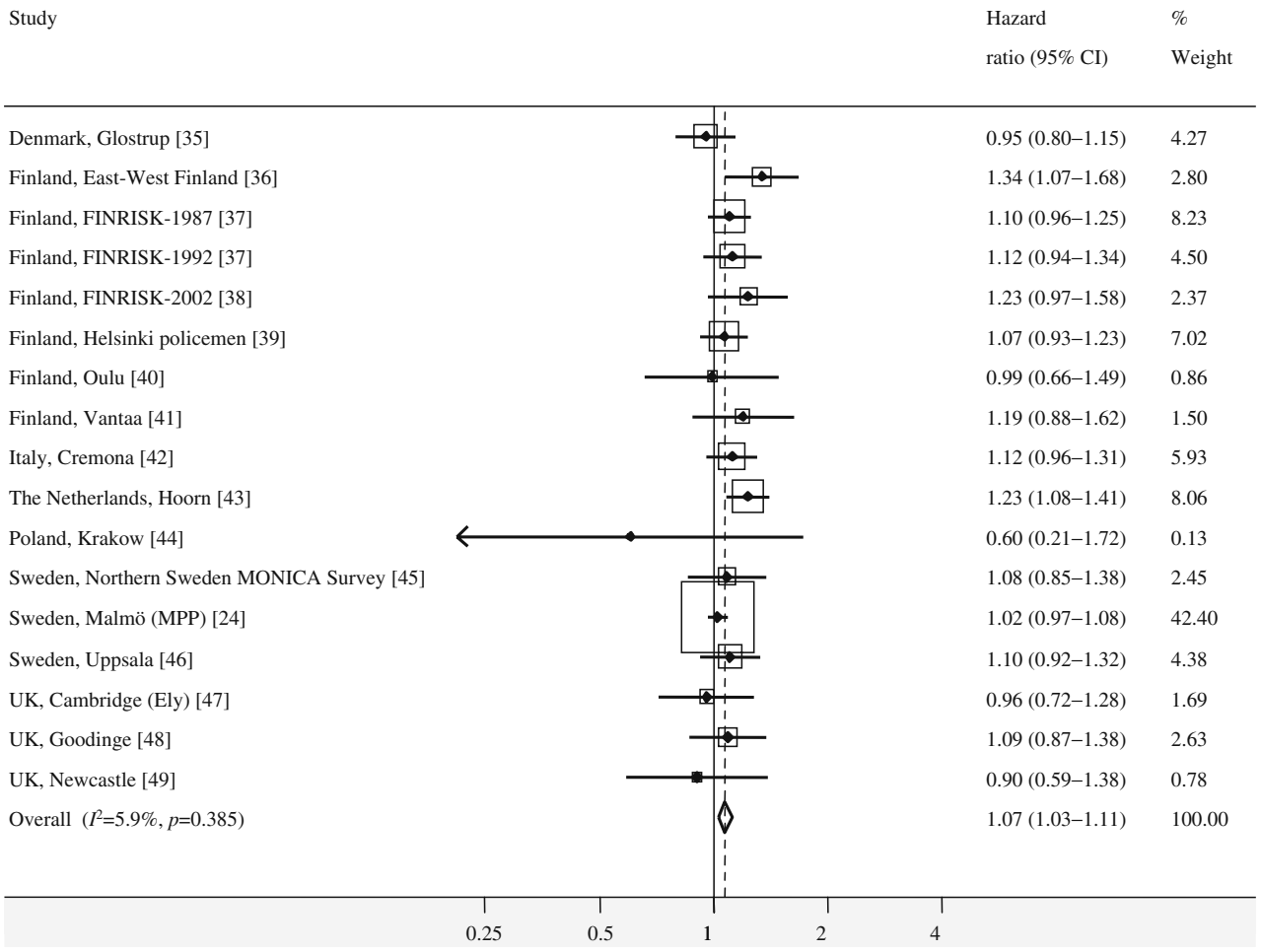


change the pooled HR for either FPG or 2-hPG. Removing the MPP study, which contributed to more than $40 \%$ weight of the overall estimate, only slightly increased the pooled HR for 2-hPG (from 1.07 [95\% CI 1.03, 1.11] to $1.11[1.06,1.17])$.

\section{Discussion}

In this collaborative study, we found that mortality from certain types of cancers, particularly from liver cancer, was significantly increased not only in diabetic but also in prediabetic populations compared with people with NGT. The risk increased with deterioration in glucose intolerance status and was highest in people with known diabetes. Cancer mortality also increased with increasing FPG and 2-hPG concentrations.

It was reported that diabetes independently predicted allcancer mortality in women in a Japanese population [15]; and mortality from cancers of colon, liver, pancreas and bladder in men and from cancers of colon, pancreas and breast in women in a US population [16]. Notably, the diagnosis of diabetes was based on self-report in these studies, those without symptoms of diabetes were not identified. The impact of previously undiagnosed diabetes and prediabetes on cancer death was therefore not determined. OGTTs were performed in the Whitehall study in the UK [17] and in the NHANES II Mortality Study in the USA [18]; neither previously diagnosed nor undiagnosed diabetes predicted cancer death in these studies, whereas IGT did so in the NHANES II Study. The number of patients with diabetes was, however, much lower in the both studies compared with our study.

Several mechanisms may be involved in the relationship between glucose intolerance and the risk of cancer mortality. Oxidative stress and accumulated advanced glycation end-products induced by hyperglycaemia at the cellular level may play important roles in cancer development and progression [27]. Hyperinsulinaemia and increased level of bioavailable insulin-like growth factor I related to insulin resistance [28] may promote cancer cell proliferation [29] and may also relate to worse cancer outcome [29]. In our study, adjustment for fasting insulin did not alter the relationship between glucose intolerance and all-cancer death. Treatment choices for cancer patients with diabetes may be limited by the presence of hyperglycaemia and co-existing diabetes complications [30] and certain types of cancer may be treated less aggressively in patients with diabetes as a comorbidity than in patients without diabetes [11], which may also lead to the worse cancer survival in patients with diabetes. Although certain glucose-lowering agents have been reported to increase the risk of cancer incidence [10] and cancer mortality [31], the overall effect of glucoselowering treatments on cancer mortality in our study population is unclear because the information on treatment was not available in detail.

The collaborative data analysis with a relatively large number of all-cancer death events accumulated increased statistical power, and enabled data analysis for site-specific cancers in subgroups. The effect of glucose intolerance on cancer mortality was homogeneous across studies. Diabetes was classified based on a standard 2 h 75 g OGTT, which was not available in similar studies previously reported. There were, however, several limitations with the data. First, the date of cancer diagnosis was not documented; the actual onset of prediabetes and undiagnosed diabetes was also not known in one cross-sectional survey; as a result, the direction of a causative relationship, if any, between glucose intolerance and certain types of cancer such as cancer of the pancreas cannot be determined. Second, the duration of known diabetes, data on detailed treatments for diabetic patients at baseline and during follow-up were not available; the effect of glucose-lowering agents on the risk of cancer death cannot be estimated. Third, alcohol consumption and history of hepatitis and cirrhosis were not recorded in the present study, which might confound the effect of glucose intolerance on risk of death from liver cancer. Dietary factors and physical activity were also potential confounders but not available in this study. Fourth, $\mathrm{HbA}_{1 \mathrm{c}}$ was not determined and individuals who met only $\mathrm{HbA}_{1 \mathrm{c}}$ criteria for diabetes [32] might have been misclassified as prediabetes or NGT [33, 34], which might have obscured the relationship between diabetes and cancer mortality. This needs to be further investigated.

In conclusion, the present study confirmed that diabetes and prediabetes are independent risk predictors for allcancer death, particularly death from liver cancer. In individuals without known diabetes, FPG and 2-hPG concentrations are positively related to the risk of allcancer death.

Acknowledgements The data analysis was sponsored by a grant from the Academy of Finland (118492).

Duality of interest R. Heine is an employee and stock holder of Eli Lilly and company. The other authors declare that there is no duality of interest associated with this manuscript.

\section{References}

1. Huxley R, Ansary-Moghaddam A, Berrington de Gonzalez A, Barzi F, Woodward M (2005) Type-II diabetes and pancreatic cancer: a meta-analysis of 36 studies. Br J Cancer 92:2076-2083

2. Larsson SC, Orsini N, Wolk A (2005) Diabetes mellitus and risk of colorectal cancer: a meta-analysis. J Natl Cancer Inst 97:1679-1687 
3. El-Serag HB, Hampel H, Javadi F (2006) The association between diabetes and hepatocellular carcinoma: a systematic review of epidemiologic evidence. Clin Gastroenterol Hepatol 4:369-380

4. Larsson SC, Orsini N, Brismar K, Wolk A (2006) Diabetes mellitus and risk of bladder cancer: a meta-analysis. Diabetologia 49:2819-2823

5. Friberg E, Orsini N, Mantzoros CS, Wolk A (2007) Diabetes mellitus and risk of endometrial cancer: a meta-analysis. Diabetologia 50:1365-1374

6. Larsson SC, Mantzoros CS, Wolk A (2007) Diabetes mellitus and risk of breast cancer: a meta-analysis. Int J Cancer 121:856-862

7. Mitri J, Castillo J, Pittas AG (2008) Diabetes and risk of nonHodgkin's lymphoma: a meta-analysis of observational studies. Diab Care 31:2391-2397

8. Jonasson JM, Ljung R, Talback M, Haglund B, Gudbjornsdottir S, Steineck G (2009) Insulin glargine use and short-term incidence of malignancies - a population-based follow-up study in Sweden. Diabetologia 52:1745-1754

9. Hemkens LG, Grouven U, Bender R et al (2009) Risk of malignancies in patients with diabetes treated with human insulin or insulin analogues: a cohort study. Diabetologia 52:1732-1744

10. Currie CJ, Poole CD, Gale EA (2009) The influence of glucoselowering therapies on cancer risk in type 2 diabetes. Diabetologia 52:1766-1777

11. van de Poll-Franse LV, Houterman S, Janssen-Heijnen ML, Dercksen MW, Coebergh JW, Haak HR (2007) Less aggressive treatment and worse overall survival in cancer patients with diabetes: a large population based analysis. Int $\mathrm{J}$ Cancer 120:1986-1992

12. Landman GW, Ubink-Veltmaat LJ, Kleefstra N, Kollen BJ, Bilo HJ (2008) Increased cancer mortality in type 2 diabetes (ZODIAC-3). Anticancer Res 28:1373-1375

13. Tseng CH, Chong CK, Tai TY (2009) Secular trend for mortality from breast cancer and the association between diabetes and breast cancer in Taiwan between 1995 and 2006. Diabetologia 52:240-246

14. Tseng CH, Chong CK, Tseng CP, Chan TT (2009) Age-related risk of mortality from bladder cancer in diabetic patients: a 12-year followup of a national cohort in Taiwan. Ann Med 41:371-379

15. Oba S, Nagata C, Nakamura K, Takatsuka N, Shimizu H (2008) Selfreported diabetes mellitus and risk of mortality from all causes, cardiovascular disease, and cancer in Takayama: a population-based prospective cohort study in Japan. J Epidemiol 18:197-203

16. Coughlin SS, Calle EE, Teras LR, Petrelli J, Thun MJ (2004) Diabetes mellitus as a predictor of cancer mortality in a large cohort of US adults. Am J Epidemiol 159:1160-1167

17. Batty GD, Shipley MJ, Marmot M, Smith GD (2004) Diabetes status and post-load plasma glucose concentration in relation to site-specific cancer mortality: findings from the original Whitehall study. Cancer Causes Control 15:873-881

18. Saydah SH, Loria CM, Eberhardt MS, Brancati FL (2003) Abnormal glucose tolerance and the risk of cancer death in the United States. Am J Epidemiol 157:1092-1100

19. Jee SH, Ohrr H, Sull JW, Yun JE, Ji M, Samet JM (2005) Fasting serum glucose level and cancer risk in Korean men and women. JAMA 293:194-202

20. Stocks T, Rapp K, Bjorge T et al (2009) Blood glucose and risk of incident and fatal cancer in the metabolic syndrome and cancer project (me-can): analysis of six prospective cohorts. PLoS Med 6:e1000201

21. Levine W, Dyer AR, Shekelle RB, Schoenberger JA, Stamler J (1990) Post-load plasma glucose and cancer mortality in middleaged men and women. 12-year follow-up findings of the Chicago Heart Association Detection Project in Industry. Am J Epidemiol 131:254-262

22. DECODE Study Group on behalf of the European Diabetes Epidemiology Study Group (1998) Will new diagnostic criteria for diabetes mellitus change phenotype of patients with diabetes? Reanalysis of European epidemiological data. DECODE Study Group on behalf of the European Diabetes Epidemiology Study Group. BMJ 317:371-375

23. DECODE Study Group on behalf of the European Diabetes Epidemiology Study Group (1999) Glucose tolerance and mortality: comparison of WHO and American Diabetes Association diagnostic criteria. The DECODE study group. European Diabetes Epidemiology Group. Diabetes Epidemiology: Collaborative analysis Of Diagnostic criteria in Europe. Lancet 354:617-621

24. Berglund G, Nilsson P, Eriksson KF et al (2000) Long-term outcome of the Malmo preventive project: mortality and cardiovascular morbidity. J Intern Med 247:19-29

25. Alberti KG, Zimmet PZ (1998) Definition, diagnosis and classification of diabetes mellitus and its complications. Part 1: diagnosis and classification of diabetes mellitus provisional report of a WHO consultation. Diabet Med 15:539-553

26. Higgins JP, Thompson SG, Deeks JJ, Altman DG (2003) Measuring inconsistency in meta-analyses. BMJ 327:557-560

27. Abe R, Yamagishi S (2008) AGE-RAGE system and carcinogenesis. Curr Pharm Des 14:940-945

28. Rajpathak SN, Gunter MJ, Wylie-Rosett J et al (2009) The role of insulin-like growth factor-I and its binding proteins in glucose homeostasis and type 2 diabetes. Diabetes Metab Res Rev 25:312

29. Pollak M (2008) Insulin and insulin-like growth factor signalling in neoplasia. Nat Rev Cancer 8:915-928

30. Richardson LC, Pollack LA (2005) Therapy insight: Influence of type 2 diabetes on the development, treatment and outcomes of cancer. Nat Clin Pract Oncol 2:48-53

31. Bowker SL, Majumdar SR, Veugelers P, Johnson JA (2006) Increased cancer-related mortality for patients with type 2 diabetes who use sulfonylureas or insulin. Diab Care 29:254-258

32. The International Expert Committee (2009) International Expert Committee Report on the Role of the A1C Assay in the Diagnosis of Diabetes. Diab Care 32:1327-1334

33. Tanaka Y, Atsumi Y, Matsuoka K et al (2001) Usefulness of stable HbA1c for supportive marker to diagnose diabetes mellitus in Japanese subjects. Diab Res Clin Pract 53:41-45

34. Zhou XH, Ji LN, Luo YY, Zhang XY, Han XY, Qiao Q (2009) Performance of $\mathrm{HbA}(1 \mathrm{c})$ for detecting newly diagnosed diabetes and pre-diabetes in Chinese communities living in Beijing. Diabet Med 26:1262-1268

35. Schroll M, Hagerup L (1979) Relationship of fasting blood glucose to prevalence of ECG abnormalities and $10 \mathrm{yr}$ risk of mortality from cardiovascular diseases in men born in 1914: from the Glostrup population studies. J Chron Dis 32:699707

36. Stengard JH, Tuomilehto J, Pekkanen J et al (1992) Diabetes mellitus, impaired glucose tolerance and mortality among elderly men: the Finnish cohorts of the Seven Countries Study. Diabetologia 35:760-765

37. Vartiainen E, Jousilahti P, Alfthan G, Sundvall J, Pietinen P, Puska P (2000) Cardiovascular risk factor changes in Finland, 19721997. Int J Epidemiol 29:49-56

38. Borodulin K, Laatikainen T, Lahti-Koski M et al (2005) Associations between estimated aerobic fitness and cardiovascular risk factors in adults with different levels of abdominal obesity. Eur J Cardiovasc Prev Rehabil 12:126-131

39. Pyorala K, Savolainen E, Lehtovirta E, Punsar S, Siltanen P (1979) Glucose tolerance and coronary heart disease: Helsinki Policemen Study. J Chron Dis 32:729-745

40. Rajala U, Qiao Q, Laakso M, Keinanen-Kiukaanniemi S (2000) Antihypertensive drugs as predictors of type 2 diabetes among subjects with impaired glucose tolerance. Diab Res Clin Pract $50: 231-239$ 
41. Strandberg TE, Tilvis RS, Lindberg O et al (1996) High plasma insulin is associated with lower LDL cholesterol in elderly individuals. Atherosclerosis 121:267-273

42. Garancini MP, Calori G, Ruotolo G et al (1995) Prevalence of NIDDM and impaired glucose tolerance in Italy: an OGTT-based population study. Diabetologia 38:306-313

43. Beks PJ, Mackaay AJ, de Neeling JN, de Vries H, Bouter LM, Heine RJ (1995) Peripheral arterial disease in relation to glycaemic level in an elderly Caucasian population: the Hoorn Study. Diabetologia 38:86-96

44. Pajak A, Williams OD, Broda G et al (1997) Changes over time in blood lipids and their correlates in Polish rural and urban populations: the Poland-United States Collaborative Study in cardiopulmonary disease epidemiology. Ann Epidemiol 7:115-124

45. Rautio A, Eliasson M, Stegmayr B (2008) Favorable trends in the incidence and outcome in stroke in nondiabetic and diabetic subjects: findings from the Northern Sweden MONICA Stroke Registry in 1985 to 2003. Stroke 39:3137-3144

46. Skarfors ET, Selinus KI, Lithell HO (1991) Risk factors for developing non-insulin dependent diabetes: a 10 year follow up of men in Uppsala. BMJ 303:755-760

47. Wareham NJ, Byrne CD, Williams R, Day NE, Hales CN (1999) Fasting proinsulin concentrations predict the development of type 2 diabetes. Diab Care 22:262-270

48. Gould MM, Mohamed-Ali V, Goubet SA, Yudkin JS, Haines AP (1993) Microalbuminuria: associations with height and sex in non-diabetic subjects. BMJ 306:240-242

49. Unwin N, Harland J, White M et al (1997) Body mass index, waist circumference, waist-hip ratio, and glucose intolerance in Chinese and Europid adults in Newcastle, UK. J Epidemiol Community Health 51:160-166 